\title{
Nutraceuticals and herbal extracts: A ray of hope for COVID-19 and related infections (Review)
}

\author{
AHMED HAMZA TAHIR ${ }^{1}$, MUHAMMAD MOHSIN JAVED ${ }^{2}$ and ZAHID HUSSAIN ${ }^{3}$ \\ ${ }^{1}$ Institute of Biochemistry and Biotechnology, University of the Punjab, Lahore, Punjab 54590; \\ ${ }^{2}$ Office of the Registrar, Virtual University of Pakistan, Lahore, Punjab 55150; ${ }^{3}$ Institute of Industrial Biotechnology, \\ Government College University, Lahore, Punjab 54000, Pakistan
}

Received May 16, 2020; Accepted August 27, 2020

DOI: $10.3892 /$ ijfn.2020.6

\begin{abstract}
The global pandemic caused by the novel coronavirus disease 2019 (COVID-19), for which there is no effective vaccine or treatment available yet, has led to a global health emergency. Despite a lack of clinical data, compelling evidence from the literature suggests that certain nutraceuticals (such as omega-3 fats, $\beta$-glucans, amino acids, probiotics, vitamins and minerals) and plant-based compounds derived from herbal extracts may potentially be used in the treatment of COVID-19. In the present review article, the benefits of such natural products in treating various respiratory complications are highlighted, and it is tentatively suggested that these benefits could be extrapolated to COVID-19. These natural compounds may not only modulate the immunity of a susceptible population, but may also pave the way towards the development of drugs which may be used to treat COVID-19. Although attention has recently focused on these compounds in this context, further clinical and experimental studies are required to validate their efficacy. It is thus suggested that the in vitro and in vivo evaluation of these compounds be carried out as soon as possible, in order to counteract the ongoing increase in the number of cases of COVID-19.
\end{abstract}

\section{Contents}

1. Introduction

2. Therapeutic benefits of nutraceuticals for respiratory complications

3. Therapeutic benefits of herbal extracts for respiratory complications

4. Conclusion

Correspondence to: Mr. Ahmed Hamza Tahir, Institute of Biochemistry and Biotechnology, University of the Punjab, Quaid-i-Azam Campus, Canal Road, Lahore, Punjab 54590, Pakistan

E-mail: ahmedhamzatahir@yahoo.com

Key words: coronavirus, COVID-19, human health, nutraceuticals, herbal, phytochemicals, natural products

\section{Introduction}

Coronavirus disease 2019 (COVID-19). Global health is threatened by an ongoing outbreak of COVID-19, a respiratory disease caused by the novel coronavirus, SARS-CoV-2, which was first identified in December, 2019 in Wuhan, China (1). As of August 28, 2020,>24.7 million individuals had been infected with the virus worldwide, and approximately 838,000 have succumbed to the disease (2). In total, seven types of coronaviruses, namely severe acute respiratory syndrome coronavirus (SARS-CoV), Middle East respiratory syndrome coronavirus (MERS-CoV), severe acute respiratory syndrome coronavirus 2 (SARS-CoV-2), OC43, NL63, 229E and HKU1, are known to infect humans. Of these, the first three can cause fatal infections, whereas the latter four typically cause mild common cold-associated symptoms, particularly in immunocompromised individuals (3). COVID-19 is highly contagious and infected patients exhibit symptoms of fever, pneumonia, thrombocytopenia, cough, dyspnea, myalgia and asthenia (4).

Prevention and treatment of COVID-19. As of August 5, 2020, no vaccine or successful treatment for COVID-19 has been reported and only supportive care, personal protection, early diagnosis and isolation are available to reduce the spread and severity of the infection (5). Huang et al (6) reported that patients with COVID-19 develop acute respiratory distress syndrome, followed by anemia, acute heart injuries and secondary infections. Empirical therapy with antibiotics (including cephalosporins, azithromycin, vancomycin, quinolones, tigecycline and carbapenems), antivirals (including lopinavir, ritonavir, remdesivir and oseltamivir) and corticosteroids (including dexamethasone and methylprednisolone) has thus been used for the treatment of patients with COVID-19 (7). The clinical efficacy of all of these treatments, however, warrants further confirmation.

Potential agents with which to combat COVID-19. Research proposals and clinical trials have suggested that some treatments, including supplements and phytochemicals, have the potential to help fight coronavirus infection. A recent study suggested that the risk of becoming infected could be reduced by vitamin D3 supplementation. Serum concentrations $>40-60 \mathrm{ng} / \mathrm{ml}(100-150 \mathrm{nmol} / \mathrm{l})$ were suggested to be 
required in order to prevent infection, with even higher doses required to treat patients already infected (8). In addition, due to its antiviral and immunomodulatory properties, zinc supplementation may also be considered for use in the prevention or treatment of COVID-19 (9). Zhang et al (10) proposed that melatonin, which has antioxidant and anti-inflammatory properties, together with a good safety profile, and also potentially modulates the immune system, improves sleep quality, and reduces vessel permeability, anxiety and the use of sedatives, may lead to better clinical outcomes for patients with COVID-19. Ang et al (11) analyzed the potential of traditional herbal medicines, which contained a total of 56 herbs, for the treatment of patients with COVID-19. The detailed review by Islam et al (12) also reported that a wide range of herbal compounds, including tylophorine, lycorine, ouabain, silvestrol, homoharringtonine and 7-methoxycryptopleurine, broadly suppressed different coronaviruses, with $\mathrm{IC}_{50}$ values ranging from 12 to $143 \mathrm{nM}$. Yu et al (13) also demonstrated that the plant-derived flavonoids, myricetin and scutellarein, are inhibitors of SARS-CoV helicase. Collectively, the above-mentioned studies suggest that natural products and dietary supplements may help in the fight against COVID-19. A pictorial representation of the potential beneficial effects of nutraceuticals and herbal extracts against COVID-19 is depicted in Fig. 1.

SARS, SARS-CoV-2 and MERS are known as enveloped viruses (14), and several bioactive lipids, including omega-3 fatty acids, such as eicosapentaenoic acid (EPA) and docosahexaenoic acid (DHA), have been reported to inactivate these enveloped viruses and reduce their proliferation (15). Some metabolites of EPA and arachidonic acid, such as thromboxanes, leukotrienes and prostaglandins, induce inflammation (16), whereas other metabolites of EPA and DHA, such as maresins, protectins, resolvins and lipoxins, suppress inflammation, modulate the T-cell response, reduce microbial load, augment phagocytosis and enhance wound healing processes. These latter bioactive lipids can be used in the treatment of airway inflammation and common human lung diseases, such as chronic obstructive pulmonary disease (COPD) and asthma $(17,18)$. A recent study revealed that both EPA and DHA, from fish oil, improved breathing for patients with asthma (19). The oral or intravenous administration of EPA or DHA could, therefore, potentially promote the recovery of patients with COVID-19 (20).

With regards to the recent increase in the number of published articles on COVID-19, including reports of infected cases, fatalities, disease severity and vulnerability (21), the purpose of the present review article is to draw the attention of medical and pharmacy professionals towards nutraceuticals and herbal extracts for the treatment of COVID-19. The present review focuses on reported facts and figures to highlight the potential of natural products to strengthen the immunity of the general population, and to pave the way for the identification of drugs which may be used in the treatment of patients with COVID-19. Mathematical models predict that reported numbers of cases of COVID-19 will continue to increase until a vaccine is made available to the global market (22). The present review article highlights the therapeutic significance of some promising natural products with activity against viruses in general, and COVID-19 in particular.

\section{Therapeutic benefits of nutraceuticals for respiratory complications}

Vitamins. A daily intake of 20-50 $\mu \mathrm{g}$ of vitamin D was recently recommended for obese individuals, healthcare workers and smokers in order to enhance their resistance to COVID-19 infection (23). Yalaki et al (24) reported that supplementation with vitamin D in patients suffering from acute bronchiolitis increased immunity and normalized pulmonary function. Other studies have also associated the administration of vitamin $\mathrm{D}$ with the reduced likelihood of developing respiratory infections $(25,26)$. The administration of high-dose vitamin C (1,000-6,000 mg) has also been reported to decrease the time spent by critically ill patients on mechanical ventilation by $25 \%$, and also reduced their length of stay in an intensive care unit (27). Of note, vitamin $\mathrm{C}$ has also been proven to be effective against asthma induced by the common cold $(28,29)$.

\section{Dietary minerals}

Selenium. The importance of selenium for optimal immune function has been emphasized in the literature (30). Selenium provides resistance against viral infections through its redox homeostasis and antioxidant properties (31). Selenium deficiency has been associated with impaired immune function, likely due to increased oxidative stress in the host organism (32). This can lead to alterations in the viral genome, which may increase virulence and boost pathogenicity (33). Dietary selenium has been shown to improve immunity against the lethal H1N1 influenza virus infection (34-36) and can also be potentially used in the current battle against COVID-19 (37).

Zinc. Elderly individuals are often deficient in zinc, which is essential for immune function, and zinc deficiency is considered to be a potential risk factor for the development of pneumonia among the elderly $(38,39)$. Barnett et al $(40)$ found that older subjects with higher serum zinc concentrations $(>70 \mu \mathrm{g} / \mathrm{dl})$ were not only characterized by a lower incidence of pneumonia $(\mathrm{P}<0.001)$, but also with a lower duration of disease and less need for antibiotics than older patients with low serum zinc concentrations $(<70 \mu \mathrm{g} / \mathrm{dl})$. Other studies have demonstrated that zinc deficiency is associated with an up to $80 \%$ higher incidence of pneumonia in children $(41,42)$ and zinc supplementation has also been reported to significantly decrease the development of respiratory diseases among children suffering from acute lower respiratory tract infections (43). A previous in vitro study also indicated that zinc salts inhibited the replication of respiratory syncytial virus (RSV) and prevent cell-to-cell spread in human epithelial type 2 (HEp-2) cells (44). Zinc is considered to be essential for the respiratory epithelium due to its anti-inflammatory and antioxidant activities, along with its ability to regulate tight junction proteins, including claudin-1 and Zonula occludens-1 $(45,46)$. In a separate study, the length of cilia at the bronchial epithelium of zinc-deficient rats was shown to be improved by zinc supplementation (47). In vitro experiments in the study by Woodworth et al (48) highlighted the ability of zinc to boost mucociliary clearance by enhancing the beat frequency of cilia. Zinc ions have also been found to inhibit the RNA-dependent RNA polymerases of influenza virus, hepatitis $\mathrm{C}$ virus (HCV) and rhinoviruses, and to impair the 


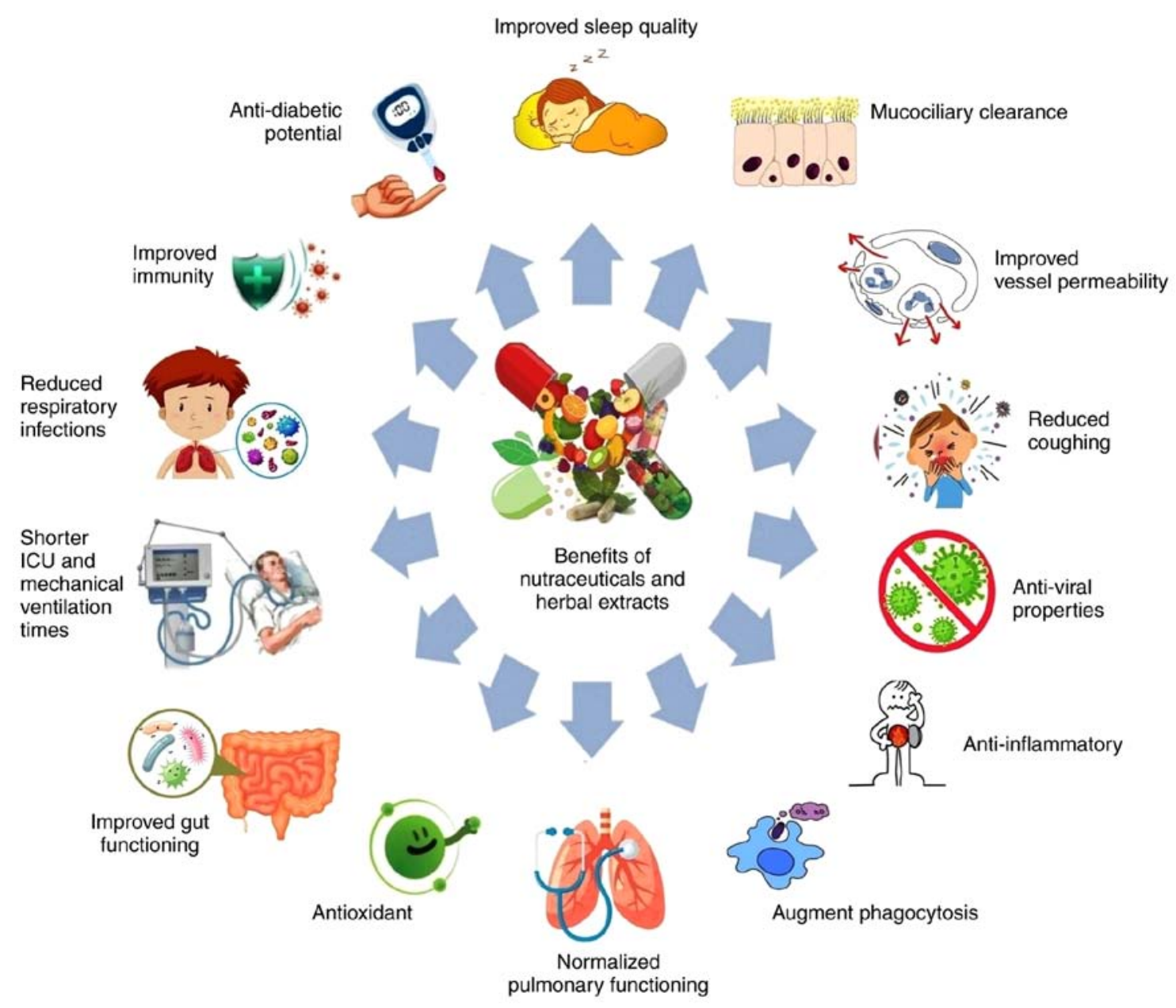

Figure 1. Schematic diagram illustrating the potential beneficial effects of nutraceuticals and herbal extracts in the management of COVID-19.

activity of the RNA-synthesizing machinery of nidoviruses, the order of viruses to which SARS-CoV-2 belongs $(49,50)$.

Iron. Whereas excessively high serum concentrations of iron can cause oxidative stress and lead to viral mutations, iron deficiency can impair host immunity and increase susceptibility to infections (51). The dysregulated homeostasis of iron, which alters serum concentrations, has been associated with several respiratory diseases, including asthma, cystic fibrosis, COPD, idiopathic pulmonary fibrosis, acute respiratory tract infections and lung cancer $(52,53)$. The strict regulation of serum iron concentration could thus provide favorable clinical outcomes for patients with COVID-19.

$N$-acetyl-cysteine (NAC). NAC, which is derived from the naturally occurring amino acid, cysteine, is most commonly prescribed to patients suffering from various respiratory complications, including respiratory tract infections, idiopathic pulmonary fibrosis and chronic bronchitis (54-56). The antioxidant and mucolytic effects of NAC have been reported to significantly improve the function of airways and to reduce COPD exacerbations (57). NAC treatment has also been reported to inhibit the RSV infection of human alveolar epithelial (A549) cells and to reduce mucin release (58). In a previous review article, Sadowska (59) concluded that NAC may be beneficial in the management of COPD, since it would promote clearance of mucus and alleviate oxidative stress and inflammation. Taken together, these results demonstrate the clear potential of NAC as an adjuvant supplement for COVID-19 patients $(60,61)$.

\section{Amino acids}

Arginine. Arginine has been reported to act synergistically with virucidal conditions, such as high temperatures and acidic $\mathrm{pH}$ levels, and can thus potentially inactivate enveloped viruses $(62,63)$. Tsujimoto et al (64) successfully inactivated herpes simplex virus type 2 (HSV-2) using a solution of arginine. Similarly, influenza A has been shown to be inactivated under similar conditions (65). Recently, Meingast and Heldt (63) suggested that arginine inactivates viruses through a variety of mechanisms, including pore formation and destabilization of the viral membrane, the inhibition of the function of non-structural proteins, the suppression of protein-protein interactions and aggregation. Ikeda et al (66) suggested that arginine associates with multiple sites on viral particles, thereby affecting glycoprotein-lipid interactions on the viral envelope. Due to the low cytotoxicity of arginine, a previous study demonstrated the possible use of an intranasal spray containing an aqueous solution of arginine to inhibit influenza A infection in vivo (67). In a NC/Nga mouse model of asthma, arginine was found to contribute to improved asthmatic symptoms by reducing airway inflammation in lung tissue and altering L-arginine metabolism (68). 
Glutamine (GLN). GLN is one of the most abundant free amino acids within the human body, with a concentration of approximately 500-900 $\mu \mathrm{mol} / 1$ (69). In a murine model of asthma, Lee et al (70) demonstrated that, at therapeutic doses, GLN suppressed inflammation by inhibiting the recruitment of neutrophils into the airways. In a ventilator-induced lung injury (VILI) mouse model, in which the lungs of mice are acutely injured by acid aspiration, the administration of GLN was reported to reduce the destruction of lung tissue, lung edema, cytokine production and neutrophil recruitment to the lung (71). Oliveira et al (72) proposed that exogenous GLN may be beneficial against asthma and acute respiratory distress syndrome (ARDS), and during the treatment of lung cancer. Thus, GLN may provide therapeutic benefits to COVID-19 patients (73).

Probiotics. Nutritional supplementation with probiotics has been reported to be beneficial for patients suffering from respiratory tract infections (74-76). Strasser et al (77) reported that various strains of probiotics, including Lactococcus lactis W58, Lactobacillus brevis W63, Enterococcus faecium W54, Lactobacillus acidophilus W22, Bifidobacterium lactis W51 and Bifidobacterium bifidum W23, helped to reduce the incidence of upper respiratory tract infections (URTIs) in trained athletes, without altering performance. Another probiotic strain, Lactobacillus casei Zhang, which exhibits immunomodulatory, anti-inflammatory and anti-oxidative effects, has been shown to alleviate the symptoms of URTI and restore gastrointestinal health in adults and elderly subjects (78). RSV infection has also been reported to be suppressed by various probiotic strains, including Lactobacillus gasseri SBT2055 and Lactobacillus rhamnosus CRL1505 (79,80). The results of the meta-analysis by Kang et al (81) revealed the efficacy of probiotics in the treatment of common cold infections. During the COVID-19 pandemic, the National Administration of Traditional Chinese Medicine and the Chinese National Health Commission recommended the use of probiotic therapy to control coronavirus infection (82); however, the effectiveness of probiotics in reducing the mortality rate of patients in intensive care units remains uncertain. Jayawardena et al (83) suggested the use of probiotics as a dietary supplement to prevent infection of susceptible populations with SARS-CoV-2. Since probiotics are readily available as dietary supplements and have negligible side-effects if administered at the correct doses, they may thus provide a useful intervention strategy against COVID-19 (84-86). A study to evaluate whether dietary supplementation with Lactobacillus coryniformis K8 can help to prevent healthcare workers from contracting COVID-19 was registered at ClinicalTrials.gov (NCT04366180) on April 28, 2020.

Omega-3 fatty acids. Fats, which can be classified as saturated or unsaturated, form an essential part of the human diet and play a vital role in nutrition and health $(87,88)$. Fats serve as a main source of energy, participate in cell signaling and responses, and play a structural role as part of the cell membrane. Omega-3 polyunsaturated fatty acids have been reported to confer health benefits in patients suffering from respiratory complications, such as ARDS, COPD, impaired oxygenation and pulmonary fibrosis (89-92) and are attracting considerable attention due to their anticoagulant properties and ability to reduce inflammation (93). The consumption of omega-3 polyunsaturated fatty acids has been associated with a number of physiological alterations, including the production of lung surfactants, host-microbial interactions, alterations in blood rheology and the production of endogenous eicosanoids (94).

According to the study by Miyata and Arita (95), omega-3 fatty acids can alleviate the inflammatory complications resulting from allergic reactions and asthma. Omega-3 fatty acids have also been reported to suppress the synthesis of immunoglobulin $\mathrm{E}$, leading to reduced airway inflammation and bronchoconstriction in patients with asthma (96). The lipid mediator, protectin D1, which is derived from omega-3 fatty acids, has been reported to suppress the replication of the highly pathogenic influenza H5N1 virus, and to improve the survival of H5N1-infected mice (97). Linday et al (98) found that the simultaneous administration of cod liver oil (which contains EPA and vitamin A) and a multivitamin-mineral supplement to children led to a statistically significant $(\mathrm{P}<0.05)$ decrease in the mean number of URTI-related medical consultations over time. Overall, omega-3 fatty acids confer significant health benefits to patients with URTI complications and shorten the length of stay of acutely ill patients in hospital (99-101). Since omega-3 fatty acids have proven to be effective in reducing airway inflammation and bronchoconstriction, have also exhibited efficacy against viral infections $(102,103)$, their potential for use against COVID-19 warrants further investigation (104-106).

$\beta$-glucans. $\beta$-glucans, which are potent activators of immune cells, including neutrophils, natural killer cells and macrophages, exert a favorable effect on the host defense system (107). In addition to the immunomodulatory effects, the administration of $\beta$-glucans has been shown to reduce the susceptibility of healthy subjects to URTIs and to decrease the severity of URTIs in infected subjects (108-111). $\beta$-glucans have also been shown to exhibit antiviral activity against HSV-1 $(112,113)$ and influenza virus $(114,115)$. More recently, it was suggested that $\beta$-glucans can help to reduce morbidity and mortality associated with COVID-19 $(116,117)$.

\section{Therapeutic benefits of herbal extracts for respiratory complications}

The use of phytochemicals and natural products for the treatment of various diseases is gaining worldwide attention (118,119). Prior to the discovery of antibiotics, herbal extracts played an important role in the treatment of diseases (120), and purified natural products and herbal extracts now provide a rich pool of compounds for the development of novel antiviral drugs (121). Lin et al (122) summarized the antiviral activity of various natural products and herbal medicines against some notable viral pathogens, including RSV, measles virus, dengue virus, influenza virus, human immunodeficiency virus (HIV), HSV, HCV, hepatitis B virus, enterovirus 71, coxsackievirus and coronavirus.

Cheng et al (123) examined the activity of naturally occurring triterpene glycosides (saikosaponins A, B, C and D), extracted from medicinal plants, such as Bupleurum spp., Scrophularia scorodonia and Heteromorpha spp., against coronaviruses. They found that the tested phytochemicals significantly inhibited the early stage of human coronavirus 
229E infection by interfering with viral replication, absorption and penetration. In 2008, Lau et al (124) demonstrated that an aqueous extract of the medicinal herb, Houttuynia cordata, facilitated the clearance of SARS-CoV infection in mice, both by improving the immune response and by a direct antiviral effect. Firstly, it stimulated cell-mediated immunity and, secondly, it attenuated viral replication by inhibiting pivotal viral enzymes (RNA-dependent RNA polymerase and 3CL protease) involved in the replication process. Another traditional herb, Pelargonium sidoides, has been tested clinically as a treatment for human coronavirus, influenza A virus (H1N1 and H3N2), RSV, coxsackievirus, parainfluenza virus, coughs, URTIs and gastrointestinal conditions (125-128). Licorice extract, derived from the root of Glycyrrhiza glabra, has been shown to exhibit in vitro activity against vesicular stomatitis virus, vaccinia virus, SARS-CoV, RSV and HIV-1 (129,130). Nigella sativa, also known as black seed, has emerged as a 'miracle' herb, with potential antidiabetic, antioxidant, anticancer, anti-inflammatory, bronchodilatory, immunomodulatory and pulmonary-protective activities (131,132). In 2005, Li et al screened > 200 Chinese medicinal herbs for activity against SARS-CoV and found that herbal extracts from four medicinal plants, namely Lindera aggregata, Pyrrosia lingua, Lycoris radiata and Artemisia annua, exhibited antiviral activity (133). Further fractionation and purification of the $L$. radiata extract identified lycorine as a potential candidate for the development of new anti-SARS-CoV drugs (133). Equally importantly, Cordyceps (medicinal mushrooms) have significant potential to strengthen the cardiovascular, respiratory and immune systems, and also have general antiviral and antioxidant properties (134-136). The medicinal and health-promoting attributes of therapeutic fungi have recently gained considerable attention in the field of COVID-19 research (137-139).

\section{Conclusion}

The present review attempted to highlight the potential of various nutraceuticals and herbal extracts as possible treatments for COVID-19. Although strong evidence for the potential of these compounds to combat the ongoing COVID-19 pandemic has already appeared in the literature, new evidence is gradually emerging (140). The reported clinical data are, however, still inconclusive and there are also inconsistencies within the data, since some clinical studies did not achieve the desired effects. These inconsistencies seem to be related to a number of factors, including the dose used, the heterogeneity of the target population, the plasma concentration, the beginning and duration of the treatment and the route of administration (141). Taking these factors into consideration, randomized and controlled trials are required to resolve these controversies and to clarify issues around the use of these compounds. In addition to an increase in the reported number of cases, some patients who have recovered from coronavirus are testing positive again (142). Clinical validation of compounds that could possibly help to combat the COVID-19 pandemic is thus urgently required.

\section{Acknowledgements}

The authors would like to thank International Science Editing (http://www.internationalscienceediting.com) for providing free language-editing services for this article.

\section{Funding}

No funding was received.

\section{Availability of data and materials}

Not applicable.

\section{Authors' contributions}

AHT and MMJ conceived this review. AHT wrote and revised the manuscript. All authors read and approved the final version of the manuscript.

\section{Ethics approval and consent to participate}

Not applicable.

\section{Patient consent for publication}

Not applicable.

\section{Competing interests}

The authors declare that they have no competing interests.

\section{References}

1. Zhu N, Zhang D, Wang W, Li X, Yang B, Song J, Zhao X, Huang B, Shi W, Lu R, et al: A novel coronavirus from patients with pneumonia in China, 2019. N Engl J Med 382: 727-733, 2020.

2. Worldometer. COVID-19 Coronavirus Pandemic. Dover, Delaware: Worldometers.info., 2020 Available online at: www. worldometers.info/coronavirus (accessed August 28, 2020).

3. Andersen KG, Rambaut A, Lipkin WI, Holmes EC and Garry RF: The proximal origin of SARS-CoV-2. Nat Med 26: 450-452, 2020

4. Contini C, Di Nuzzo M, Barp N, Bonazza A, De Giorgio R, Tognon $M$ and Rubino S: The novel zoonotic COVID-19 pandemic: An expected global health concern. J Infect Dev Ctries 14: 254-264, 2020.

5. Prada V, Benedetti L, Cocito D, Briani C, Orazio EN, Gallia F, Antonini G, Manganelli F, Fabrizi GM, Germano F, et al: High-dose immunoglobulin pulse therapy and risk of Covid19 infection. J Neurol: 1-3, 2020 doi: 10.1007/s00415-020-10146-5 (Epub ahead of print)

6. Huang C, Wang Y, Li X, Ren L, Zhao J, Hu Y, Zhang L, Fan G, Xu J, Gu X, et al: Clinical features of patients infected with 2019 novel coronavirus in Wuhan, China. Lancet 395: 497-506, 2020.

7. Ahmed SS: The coronavirus disease 2019 (COVID-19): A review. J Adv Med Med Res 32: 1-9, 2020

8. Grant WB, Lahore H, McDonnell SL, Baggerly CA, French CB, Aliano JL and Bhattoa HP: Evidence that vitamin D supplementation could reduce risk of influenza and COVID-19 infections and deaths. Nutrients 12: 988, 2020.

9. Zhang $\mathrm{L}$ and Liu Y: Potential interventions for novel coronavirus in China: A systematic review. J Med Virol 92: 479-490, 2020.

10. Zhang R, Wang X, Ni L, Di X, Ma B, Niu S, Liu C and Reiter RJ: COVID-19: Melatonin as a potential adjuvant treatment. Life Sci 250: 117583, 2020.

11. Ang L, Lee HW, Kim A, Lee JA, Zhang J and Lee MS: Herbal medicine for treatment of children diagnosed with COVID-19: A review of guidelines. Complement Ther Clin Pract 39: 101174, 2020.

12. Islam MT, Sarkar C, El-Kersh DM, Jamaddar S, Uddin SJ, Shilpi JA and Mubarak MS: Natural products and their derivatives against coronavirus: A review of the non-clinical and pre-clinical data. Phytother Res: Apr 4, 2020 doi: 10.1002/ptr.6700 (Epub ahead of print) 
13. Yu MS, Lee J, Lee JM, Kim Y, Chin YW, Jee JG, Keum YS and Jeong YJ: Identification of myricetin and scutellarein as novel chemical inhibitors of the SARS coronavirus helicase, nsP13. Bioorg Med Chem Lett 22: 4049-4054, 2012.

14. Ashour HM, Elkhatib WF, Rahman MM and Elshabrawy HA: Insights into the recent 2019 novel Coronavirus (SARS-CoV-2) in light of past human coronavirus outbreaks. Pathogens 9: 186, 2020.

15. Chandrasekharan JA, Marginean A and Sharma-Walia N: An insight into the role of arachidonic acid derived lipid mediators in virus associated pathogenesis and malignancies. Prostaglandins Other Lipid Mediat 126: 46-54, 2016.

16. Innes JK and Calder PC: Omega-6 fatty acids and inflammation Prostaglandins Leukot Essent Fatty Acids 132: 41-48, 2018.

17. Duvall MG and Levy BD: DHA- and EPA-derived resolvins, protectins, and maresins in airway inflammation. Eur J Pharmacol 785: 144-155, 2016.

18. Chiurchiù V, Leuti A, Dalli J, Jacobsson A, Battistini L, Maccarrone $\mathrm{M}$ and Serhan $\mathrm{CN}$ : Proresolving lipid mediators resolvin D1, resolvin D2, and maresin 1 are critical in modulating T cell responses. Sci Transl Med 8: 353ra111, 2016.

19. Ramsden CE: Breathing easier with fish oil-a new approach to preventing asthma? N Engl J Med 375: 2596-2598, 2016.

20. Das UN: Can bioactive lipids inactivate coronavirus (COVID-19)? Arch Med Res 51: 282-286, 2020.

21. Velavan TP and Meyer CG: The COVID-19 epidemic. Trop Med Int Health 25: 278-280, 2020.

22. Victor A: Mathematical predictions for COVID-19 as a global pandemic. Available at SSRN 3555879, 2020

23. McCartney DM and Byrne DG: Optimisation of Vitamin D status for enhanced immuno-protection against Covid-19. Ir Med J 113: 58, 2020.

24. Yalaki Z, Taşar MA, Oney H and Gokceoğlu AU: Comparison of viral agents and Vitamin D levels in children with acute bronchiolitis infection. J Pediatr Inf 13: e14-e20, 2019.

25. Larkin A and Lassetter J: Vitamin D deficiency and acute lower respiratory infections in children younger than 5 years: Identification and treatment. J Pediatr Health Care 28: 572-582, 2014.

26. Loeb M, Dang AD, Thiem VD, Thanabalan V, Wang B, Nguyen NB, Tran HTM, Luong TM, Singh P, Smieja M, et al Effect of Vitamin D supplementation to reduce respiratory infections in children and adolescents in Vietnam: A randomized controlled trial. Influenza Other Respir Viruses 13: 176-183, 2019.

27. Hemilä $H$ and Chalker E: Vitamin $C$ may reduce the duration of mechanical ventilation in critically ill patients: A meta-regression analysis. J Intensive Care 8: 15, 2020.

28. Hemilä H: Vitamin C and common cold-induced asthma: A systematic review and statistical analysis. Allergy Asthma Clin Immunol 9: 46, 2013

29. Jeong YJ, Kim JH, Kang JS, Lee WJ and Hwang YI: Mega-dose vitamin $\mathrm{C}$ attenuated lung inflammation in mouse asthma model. Anat Cell Biol 43: 294-302, 2010.

30. Wiesner-Reinhold M, Schreiner M, Baldermann S, Schwarz D, Hanschen FS, Kipp AP, Rowan DD, Bentley-Hewitt KL and McKenzie MJ: Mechanisms of selenium enrichment and measurement in brassicaceous vegetables, and their application to human health. Front Plant Sci 8: 1365, 2017.

31. Guillin OM, Vindry C, Ohlmann T and Chavatte L: Selenium, selenoproteins and viral infection. Nutrients 11: 2101, 2019.

32. Xu J, Gong Y, Sun Y, Cai J, Liu Q, Bao J, Yang J and Zhang Z: Impact of selenium deficiency on inflammation, oxidative stress, and phagocytosis in mouse macrophages. Biol Trace Elem Res 194: 237-243, 2020

33. Harthill M: Micronutrient selenium deficiency influences evolution of some viral infectious diseases. Biol Trace Elem Res 143 1325-1336, 2011.

34. Yu L, Sun L, Nan Y and Zhu LY: Protection from H1N1 influenza virus infections in mice by supplementation with selenium: A comparison with selenium-deficient mice. Biol Trace Elem Res 141: 254-261, 2011

35. Li Y, Lin Z, Guo M, Zhao M, Xia Y, Wang C, Xu T and Zhu B Inhibition of H1N1 influenza virus-induced apoptosis by functionalized selenium nanoparticles with amantadine through ROS-mediated AKT signaling pathways. Int J Nanomedicine 13: 2005-2016, 2018

36. Li Y, Lin Z, Gong G, Guo M, Xu T, Wang C, Zhao M, Xia Y, Tang Y,Zhong J, et al: Inhibition of H1N1 influenza virus-induced apoptosis by selenium nanoparticles functionalized with arbidol through ROS-mediated signaling pathways. J Mater Chem B Mater Biol Med 7: 4252-4262, 2019.
37. Kieliszek M and Lipinski B: Selenium supplementation in the prevention of coronavirus infections (COVID-19). Med Hypotheses 143: 109878, 2020.

38. Wessels I, Maywald M and Rink L: Zinc as a gatekeeper of immune function. Nutrients 9: 1286, 2017.

39. Pae $\mathrm{M}$ and $\mathrm{Wu} \mathrm{D}$ : Nutritional modulation of age-related changes in the immune system and risk of infection. Nutr Res 41: 14-35, 2017.

40. Barnett JB, Hamer DH and Meydani SN: Low zinc status: A new risk factor for pneumonia in the elderly? Nutr Rev 68: 30-37, 2010.

41. Walker CLF, Rudan I, Liu L, Nair H, Theodoratou E, Bhutta ZA, O'Brien KL, Campbell H and Black RE: Global burden of childhood pneumonia and diarrhoea. Lancet 381: 1405-1416, 2013.

42. Kumar NS, Jayaprakash S and Kavitha D: Low serum Zinc level-a possible Marker of severe pneumonia. J Med Sci Clin Res 5: 21554-21570, 2017.

43. Shah UH, Abu-Shaheen AK, Malik MA, Alam S, Riaz M and Al-Tannir MA: The efficacy of zinc supplementation in young children with acute lower respiratory infections: A randomized double-blind controlled trial. Clin Nutr 32: 193-199, 2013.

44. Suara RO and Crowe JE: Effect of zinc salts on respiratory syncytial virus replication. Antimicrob Agents Chemother 48: 783-790, 2004

45. Truong-Tran AQ, Carter J, Ruffin R and Zalewski PD: New insights into the role of zinc in the respiratory epithelium. Immunol Cell Biol 79: 170-177, 2001.

46. Roscioli E, Jersmann HP, Lester S, Badiei A, Fon A, Zalewski P and Hodge S: Zinc deficiency as a codeterminant for airway epithelial barrier dysfunction in an ex vivo model of COPD. Int J Chron Obstruct Pulmon Dis 12: 3503-3510, 2017.

47. Darma A, Athiyyah AF, Ranuh RG, Merbawani W, Setyoningrum RA, Hidajat B, Hidayati SN, Endaryanto A and Sudarmo SM: Zinc Supplementation effect on the bronchial cilia length, the number of cilia, and the number of intact bronchial cell in Zinc deficiency rats. Indones Biomed J 12: 78-84, 2020.

48. Woodworth BA, Zhang S, Tamashiro E, Bhargave G, Palmer JN and Cohen NA: Zinc increases ciliary beat frequency in a calcium-dependent manner. Am J Rhinol Allergy 24: 6-10, 2010.

49. Te Velthuis AJ, van den Worm SH, Sims AC, Baric RS, Snijder EJ and van Hemert MJ: $\mathrm{Zn}(2+)$ inhibits coronavirus and arterivirus RNA polymerase activity in vitro and zinc ionophores block the replication of these viruses in cell culture. PLoS Pathog 6: e1001176, 2010

50. Kumar A, Kubota Y, Chernov M and Kasuya H: Potential role of Zinc supplementation in prophylaxis and treatment of COVID-19. Med Hypotheses 144: 109848, 2020.

51. Wessling-Resnick M: Crossing the Iron gate: Why and how transferrin receptors mediate viral entry. Annu Rev Nutr 38: 431-458, 2018

52. Ali MK, Kim RY, Karim R, Mayall JR, Martin KL, Shahandeh A, Abbasian F, Starkey MR, Loustaud-Ratti V, Johnstone D, et al: Role of iron in the pathogenesis of respiratory disease. Int J Biochem Cell Biol 88: 181-195, 2017.

53. Jayaweera JAAS, Reyes M and Joseph A: Childhood iron deficiency anemia leads to recurrent respiratory tract infections and gastroenteritis. Sci Rep 9: 12637, 2019.

54. Homma S, Azuma A, Taniguchi H, Ogura T, Mochiduki Y, Sugiyama Y, Nakata K, Yoshimura K, Takeuchi $M$ and Kudoh S; Japan NAC Clinical Study Group: Efficacy of inhaled $\mathrm{N}$-acetylcysteine monotherapy in patients with early stage idiopathic pulmonary fibrosis. Respirology 17: 467-477, 2012.

55. Blasi F, Page C, Rossolini GM, Pallecchi L, Matera MG, Rogliani $\mathrm{P}$ and Cazzola $\mathrm{M}$ : The effect of $\mathrm{N}$-acetylcysteine on biofilms: Implications for the treatment of respiratory tract infections. Respir Med 117: 190-197, 2016.

56. Cazzola M, Calzetta L, Page C, Jardim J, Chuchalin AG, Rogliani P and Matera MG: Influence of $\mathrm{N}$-acetylcysteine on chronic bronchitis or COPD exacerbations: A meta-analysis. Eur Respir Rev 24: 451-461, 2015.

57. Santus P, Corsico A, Solidoro P, Braido F, Di Marco F and Scichilone N: Oxidative stress and respiratory system: Pharmacological and clinical reappraisal of $\mathrm{N}$-acetylcysteine. COPD 11: 705-717, 2014.

58. Mata M, Sarrion I, Armengot M, Carda C, Martinez I, Melero JA and Cortijo J: Respiratory syncytial virus inhibits ciliagenesis in differentiated normal human bronchial epithelial cells: Effectiveness of N-acetylcysteine. PLoS One 7: e48037, 2012.

59. Sadowska AM: N-Acetylcysteine mucolysis in the management of chronic obstructive pulmonary disease. Ther Adv Respir Dis 6: 127-135, 2012. 
60. Andreou A, Trantza S, Filippou D, Sipsas N and Tsiodras S: COVID-19: The potential role of copper and N-acetylcysteine (NAC) in a combination of candidate antiviral treatments against SARS-CoV-2. In Vivo 34: 1567-1588, 2020.

61. Jaiswal N, Bhatnagar M and Shah H: N-acetycysteine: A potential therapeutic agent in COVID-19 infection. Med Hypotheses 144: 110133, 2020.

62. Ohtake S, Arakawa T and Koyama AH: Arginine as a synergistic virucidal agent. Molecules 15: 1408-1424, 2010.

63. Meingast $C$ and Heldt CL: Arginine-enveloped virus inactivation and potential mechanisms. Biotechnol Prog 36: e2931, 2020.

64. Tsujimoto K, Uozaki M, Ikeda K, Yamazaki H, Utsunomiya H, Ichinose M, Koyama AH and Arakawa T: Solvent-induced virus inactivation by acidic arginine solution. Int $\mathrm{J}$ Mol Med 25: 433-437, 2010

65. Yamasaki H, Tsujimoto K, Koyama AH,Ejima D and Arakawa T: Arginine facilitates inactivation of enveloped viruses. J Pharm Sci 97: 3067-3073, 2008

66.Ikeda K, Yamasaki H, Minami S, Suzuki Y, Tsujimoto K, Sekino Y, Irie H, Arakawa T and Koyama AH: Arginine inactivates human herpesvirus 2 and inhibits genital herpesvirus infection. Int J Mol Med 30: 1307-1312, 2012.

67. Ikeda K, Yamasaki H, Suzuki Y, Koyama AH and Arakawa T: Novel strategy with acidic arginine solution for the treatment of influenza A virus infection. Exp Ther Med 1: 251-256, 2010.

68. Zhang R, Kubo M, Murakami I, Setiawan H, Takemoto K, Inoue K, Fujikura $\mathrm{Y}$ and Ogino K: l-Arginine administration attenuates airway inflammation by altering l-arginine metabolism in an NC/Nga mouse model of asthma. J Clin Biochem Nutr 56: 201-207, 2015.

69. Pierre JF, Heneghan AF, Lawson CM, Wischmeyer PE, Kozar RA and Kudsk KA: Pharmaconutrition review: Physiological mechanisms. JPEN J Parenter Enteral Nutr 37 (5 Suppl): 51S-65S, 2013.

70. Lee CH, Kim HK, Kim JM, Ayush O, Im SY, Oh DK and Lee HK: Glutamine suppresses airway neutrophilia by blocking cytosolic phospholipase A(2) via an induction of MAPK phosphatase-1. J Immunol 189: 5139-5146, 2012.

71. Lai CC, Liu WL and Chen CM: Glutamine attenuates acute lung injury caused by acid aspiration. Nutrients 6: 3101-3116, 2014

72. Oliveira GP, De Abreu MG, Pelosi P and Rocco PR: Exogenous glutamine in respiratory diseases: Myth or reality? Nutrients 8: $76,2016$.

73. Romano L, Bilotta F, Dauri M, Macheda S, Pujia A De Santis GL, Tarsitano MG, Merra G, Di Renzo L, Esposito E and De Lorenzo A: Short report-medical nutrition therapy for critically ill patients with COVID-19. Eur Rev Med Pharmacol Sci 24: 4035-4039, 2020.

74. West NP, Horn PL, Pyne DB, Gebski VJ, Lahtinen SJ, Fricker PA and Cripps AW: Probiotic supplementation for respiratory and gastrointestinal illness symptoms in healthy physically active individuals. Clin Nutr 33: 581-587, 2014.

75. Maldonado J, Cañabate F, Sempere L, Vela F, Sánchez AR, Narbona E, López-Huertas E, Geerlings A, Valero AD Olivares $\mathrm{M}$ and Lara-Villoslada F: Human milk probiotic Lactobacillus fermentum CECT5716 reduces the incidence of gastrointestinal and upper respiratory tract infections in infants. J Pediatr Gastroenterol Nutr 54: 55-61, 2012.

76. Ozen M, Kocabas Sandal G and Dinleyici EC: Probiotics for the prevention of pediatric upper respiratory tract infections: A systematic review. Expert Opin Biol Ther 15: 9-20, 2015.

77. Strasser B, Geiger D, Schauer M, Gostner JM, Gatterer H, Burtscher M and Fuchs D: Probiotic supplements beneficially affect tryptophan-kynurenine metabolism and reduce the incidence of upper respiratory tract infections in trained athletes: A randomized, double-blinded, placebo-controlled trial Nutrients 8: 752, 2016.

78. Hor YY, Lew LC, Lau ASY, Ong JS, Chuah LO, Lee YY, Choi SB, Rashid F, Wahid N, Sun Z, et al: Probiotic Lactobacillus case Zhang (LCZ) alleviates respiratory, gastrointestinal \& RBC abnormality via immuno-modulatory, anti-inflammatory \& anti-oxidative actions. J Funct Foods 44: 235-245, 2018.

79. Kitazawa $\mathrm{H}$ and Villena $\mathrm{J}$ : Modulation of respiratory TLR3-anti-viral response by probiotic microorganisms: Lessons learned from Lactobacillus rhamnosus CRL1505. Front Immunol 5: 201, 2014.

80. Eguchi K, Fujitani N, Nakagawa H and Miyazaki T: Prevention of respiratory syncytial virus infection with probiotic lactic acid bacterium Lactobacillus gasseri SBT2055. Sci Rep 9: 4812, 2019.
81. Kang EJ, Kim SY, Hwang IH and Ji YJ: The effect of probiotics on prevention of common cold: A meta-analysis of randomized controlled trial studies. Korean J Fam Med 34: 2-10, 2013.

82. Mak JWY, Chan FKL and Ng SC: Probiotics and COVID-19: One size does not fit all. Lancet Gastroenterol Hepatol 5: 644-645, 2020

83. Jayawardena R, Sooriyaarachchi P, Chourdakis M, Jeewandara C and Ranasinghe P: Enhancing immunity in viral infections, with special emphasis on COVID-19: A review. Diabetes Metab Syndr 14: 367-382, 2020

84. Morais AHA, Passos TS, Maciel BLL and da Silva-Maia JK: Can probiotics and diet promote beneficial immune modulation and purine control in coronavirus infection? Nutrients 12: 1737, 2020.

85. Infusino F, Marazzato M, Mancone M, Fedele F, Mastroianni CM, Severino P, Ceccarelli G, Santinelli L, Cavarretta E, Marullo AGM, et al: Diet supplementation, probiotics, and Nutraceuticals in SARS-CoV-2 infection: A scoping review. Nutrients 12: 1718, 2020.

86. Baud D, Agri VD, Gibson GR, Reid G and Giannoni E Using probiotics to flatten the curve of coronavirus disease COVID-2019 pandemic. Front Public Health 8: 186, 2020.

87. Ibarguren M, López DJ and Escribá PV: The effect of natura and synthetic fatty acids on membrane structure, microdomain organization, cellular functions and human health. Biochim Biophys Acta 1838: 1518-1528, 2014.

88. Thom G and Lean M: Is there an optimal diet for weight management and metabolic health? Gastroenterology 152: 1739-1751, 2017.

89. Lemoine S CM, Brigham EP, Woo H, Hanson CK McCormack MC, Koch A, Putcha N and Hansel NN: Omega-3 fatty acid intake and prevalent respiratory symptoms among U.S. adults with COPD. BMC Pulm Med 19: 97, 2019.

90. Escamilla-Nuñez MC, Barraza-Villarreal A, HernándezCadena L, Navarro-Olivos E, Sly PD and Romieu I: Omega-3 fatty acid supplementation during pregnancy and respiratory symptoms in children. Chest 146: 373-382, 2014.

91. Singer $\mathrm{P}$ and Shapiro H: Enteral omega-3 in acute respiratory distress syndrome. Curr Opin Clin Nutr Metab Care 12 $123-128,2009$

92. Abidi A, Kourda N, Feki M and Ben Khamsa S: Protective effect of Tunisian flaxseed oil against bleomycin-induced pulmonary fibrosis in rats. Nutr Cancer 72: 226-238, 2020.

93. Whyand T, Hurst JR, Beckles M and Caplin ME: Pollution and respiratory disease: Can diet or supplements help? A review. Respir Res 19: 79, 2018.

94. Knapp HR: Omega-3 fatty acids in respiratory diseases: A review. J Am Coll Nutr 14: 18-23, 1995

95. Miyata $\mathbf{J}$ and Arita M: Role of omega-3 fatty acids and their metabolites in asthma and allergic diseases. Allergol Int 64: 27-34, 2015.

96. Yates CM, Calder PC and Rainger GE: Pharmacology and therapeutics of omega-3 polyunsaturated fatty acids in chronic inflammatory disease. Pharmacol Ther 141: 272-282, 2014

97. Morita M, Kuba K, Ichikawa A, Nakayama M, Katahira J, Iwamoto R, Watanebe T, Sakabe S, Daidoji T, Nakamura S, et al: The lipid mediator protectin D1 inhibits influenza virus replication and improves severe influenza. Cell 153: 112-125, 2013.

98. Linday LA, Shindledecker RD, Tapia-Mendoza J and Dolitsky JN Effect of daily cod liver oil and a multivitamin-mineral supplement with selenium on upper respiratory tract pediatric visits by young, inner-city, Latino children: Randomized pediatric sites. Ann Otol Rhinol Laryngol 113: 891-901, 2004.

99. Da Boit M, Gabriel BM, Gray P and Gray SR: The effect of fish oil, vitamin D and protein on URTI incidence in young active people. Int J Sports Med 36: 426-430, 2015.

100. Philpott JD, Witard OC and Galloway SD: Applications of omega-3 polyunsaturated fatty acid supplementation for sport performance. Res Sports Med 27: 219-237, 2019

101. Langlois PL, D'Aragon F, Hardy G and Manzanares W: Omega-3 polyunsaturated fatty acids in critically ill patients with acute respiratory distress syndrome: A systematic review and meta-analysis. Nutrition 61: 84-92, 2019.

102. Calder PC: Omega-3 fatty acids and inflammatory processes: From molecules to man. Biochem Soc Trans 45: 1105-1115, 2017.

103. Imai Y: Role of omega-3 PUFA-derived mediators, the protectins, in influenza virus infection. Biochim Biophys Acta 1851: 496-502, 2015

104. Messina G, Polito R, Monda V, Cipolloni L, Di Nunno N, Di Mizio G, Murabito P, Carotenuto M, Messina A, Pisanelli D, et al: Functional role of dietary intervention to improve the outcome of COVID-19: A hypothesis of work. Int J Mol Sci 21: 3104, 2020 
105. Hammock BD, Wang W, Gilligan MM and Panigrahy D Eicosanoids: The overlooked storm in COVID-19? Am J Pathol 190: 1782-1788, 2020.

106. Torrinhas RS, Calder PC, Lemos GO and Waitzberg DL: Parenteral fish oil, an adjuvant pharmacotherapy for COVID-19? Nutrition 81: 110900, 2020.

107. De Marco Castro E, Calder PC and Roche HM: $\beta$-1,3/1,6-glucans and immunity: State of the art and future directions. Mol Nutr Food Res: e1901071, 2020 doi: 10.1002/mnfr.201901071 (Epub ahead of print).

108. Murphy EA, Davis JM, Brown AS, Carmichael MD, Carson JA, Van Rooijen N, Ghaffar A and Mayer EP: Benefits of oat $\beta$-glucan on respiratory infection following exercise stress: Role of lung macrophages. Am J Physiol Regul Integr Comp Physiol 294: R1593-R1599, 2008.

109. Dharsono T, Rudnicka K, Wilhelm M and Schoen C: Effects of yeast $(1,3)-(1,6)$-beta-glucan on severity of upper respiratory tract infections: a double-blind, randomized, placebo-controlled study in healthy subjects. J Am Coll Nutr 38: 40-50, 2019.

110. Jesenak M, Urbancikova I and Banovcin P: Respiratory tract infections and the role of biologically active polysaccharides in their management and prevention. Nutrients 9: 779, 2017.

111. Talbott $\mathrm{S}$ and Talbott J: Effect of BETA 1, 3/1, 6 GLUCAN on upper respiratory tract infection symptoms and mood state in marathon athletes. J Sports Sci Med 8: 509-515, 2009.

112. Urbancikova I, Hudackova D, Majtan J, Rennerova Z, Banovcin $P$ and Jesenak M: Efficacy of Pleuran ( $\beta$-Glucan from Pleurotus ostreatus) in the management of herpes simplex virus type 1 infection. Evid Based Complement Alternat Med 2020: $8562309,2020$.

113. Murphy EA, Davis JM, Brown AS, Carmichael MD, Ghaffar A and Mayer EP: Effects of oat $\beta$-glucan on the macrophage cytokine response to herpes simplex virus 1 infection in vitro. J Interferon Cytokine Res 32: 362-367, 2012.

114. Muramatsu D, Iwai A, Aoki S, Uchiyama H, Kawata K, Nakayama Y, Nikawa Y, Kusano, K, Okabe M and Miyazaki T: $\beta$-glucan derived from Aureobasidium pullulans is effective for the prevention of influenza in mice. PLoS One 7: e41399, 2012.

115. Vetvicka V and Vetvickova J: Glucan supplementation enhances the immune response against an influenza challenge in mice. Ann Transl Med 3: 22, 2015.

116. Geller A and Yan J: Could the induction of trained immunity by $\beta$-Glucan serve as a defense against COVID-19? Front Immunol 11: 1782, 2020.

117. Murphy EJ, Masterson C, Rezoagli E, O'Toole D, Major I, Stack GD, Lynch M, Laffey JG and Rowan NJ: $\beta$-Glucan extracts from the same edible shiitake mushroom Lentinus edodes produce differential in-vitro immunomodulatory and pulmonary cytoprotective effects-Implications for coronavirus disease (COVID-19) immunotherapies. Sci Total Environ 732 139330, 2020.

118. Singh S, Sharma B, Kanwar SS and Kumar A: Lead phytochemicals for anticancer drug development. Front Plant Sci 7 : 1667, 2016.

119. Altemimi A, Lakhssassi N, Baharlouei A, Watson DG and Lightfoot DA: Phytochemicals: Extraction, isolation, and identification of bioactive compounds from plant extracts. Plants 6 : 42, 2017.

120. Prasanna G, Ujwal A, Diliprajudominic S, Marimuthu T and Saraswathi NT: A new pipeline to discover antimycotics by inhibiting ergosterol and riboflavin synthesis: The inspirations of Siddha medicine. Med Chem Res 23: 2651-2658, 2014.

121. Oliveira AF, Teixeira RR, Oliveira ASD, Souza AP, Silva MLD and Paula SO: Potential Antivirals: Natural products targeting replication enzymes of dengue and chikungunya viruses. Molecules 22: 505, 2017.

122. Lin LT, Hsu WC and Lin CC: Antiviral natural products and herbal medicines. J Tradit Complement Med 4: 24-35, 2014.

123. Cheng PW, Ng LT, Chiang LC and Lin CC: Antiviral effects of saikosaponins on human coronavirus $229 \mathrm{E}$ in vitro. Clin Exp Pharmacol Physiol 33: 612-616, 2006.

124. Lau KM, Lee KM, Koon CM, Cheung CS, Lau CP, Ho HM, Lee MY, Au SW, Cheng CH, Lau CB, et al: Immunomodulatory and anti-SARS activities of Houttuynia cordata. J Ethnopharmacol 118: 79-85, 2008.

125. Maree JE and Viljoen AM: Phytochemical distinction between Pelargonium sidoides and Pelargonium reniforme-A quality control perspective. S Afr J Bot 82: 83-91, 2012.
126. Careddu D and Pettenazzo A: Pelargonium sidoides extract EPs 7630: A review of its clinical efficacy and safety for treating acute respiratory tract infections in children. Int J Gen Med 11: 91-98, 2018

127. Baars EW, Zoen EBV, Breitkreuz T, Martin D, Matthes H, von Schoen-Angerer T, Soldner G, Vagedes J, van Wietmarschen $\mathrm{H}$, Patijn $\mathrm{O}$, et al: The contribution of complementary and alternative medicine to reduce antibiotic use: A narrative review of health concepts, prevention, and treatment strategies. Evid Based Complement Alternat Med 2019: 5365608, 2019.

128. Michaelis M, Doerr HW and Cinatl J Jr: Investigation of the influence of EPs ${ }^{\circledR} 7630$, a herbal drug preparation from Pelargonium sidoides, on replication of a broad panel of respiratory viruses. Phytomedicine 18: 384-386, 2011.

129. Fiore C, Eisenhut M, Krausse R, Ragazzi E, Pellati D, Armanini D and Bielenberg J: Antiviral effects of Glycyrrhiza species. Phytother Res 22: 141-148, 2008.

130. Feng Yeh C, Wang KC, Chiang LC, Shieh DE, Yen MH and San Chang J: Water extract of licorice had anti-viral activity against human respiratory syncytial virus in human respiratory tract cell lines. J Ethnopharmacol 148: 466-473, 2013.

131. Ahmad A, Husain A, Mujeeb M, Khan SA, Najmi AK, Siddique NA, Damanhouri ZA and Anwar F: A review on therapeutic potential of Nigella sativa: A miracle herb. Asian Pac J Trop Biomed 3: 337-352, 2013.

132. Dajani EZ, Shahwan TG and Dajani NE: Overview of the preclinical pharmacological properties of Nigella sativa (black seeds): A complementary drug with historical and clinical significance. J Physiol Pharmacol 67: 801-817, 2016.

133. Li SY, Chen C, Zhang HQ, Guo HY, Wang H, Wang L, Zhang X, Hua SN, Yu J and Xiao PG: Identification of natural compounds with antiviral activities against SARS-associated coronavirus. Antiviral Res 67: 18-23, 2005.

134. Cui JD: Biotechnological production and applications of Cordyceps militaris, a valued traditional Chinese medicine. Crit Rev Biotechnol 35: 475-484, 2015.

135. Ashraf SA, Elkhalifa AE, Siddiqui AJ, Patel M, Awadelkareem AM, Snoussi M, Ashraf MS, Adnan M and Hadi S: Cordycepin for health and wellbeing: A Potent bioactive metabolite of an entomopathogenic cordyceps medicinal fungus and its nutraceutical and therapeutic potential. Molecules 25: $2735,2020$.

136. Daba G: The endless nutritional and pharmaceutical benefits of the Himalayan gold, Cordyceps; Current knowledge and prospective potentials. Biofarmasi J Nat Prod Biochem 18: 70-77, 2020.

137. Yang M, Shang YX, Tian ZY, Xiong M, Lu CL, Jiang Y, Zhang Y, Zhang YY, Jin XY, Jin QB, et al: Characteristics of registered studies for Coronavirus disease 2019 (COVID-19): A systematic review. Integr Med Res 9: 100426, 2020.

138. Boone HA, Medunjanin D and Sijerčić A: Review on potential of phytotherapeutics in fight against COVID-19. Int J Innov Sci Res Technol 5: 481-491, 2020.

139. Suwannarach N, Kumla J, Sujarit K, Pattananandecha T, Saenjum C and Lumyong S: Natural bioactive compounds from fungi as potential candidates for protease inhibitors and immunomodulators to apply for coronaviruses. Molecules 25: $1800,2020$.

140. Umesh, Kundu D, Selvaraj C, Singh SK and Dubey VK: Identification of new anti-nCoV drug chemical compounds from Indian spices exploiting SARS-CoV-2 main protease as target. J Biomol Struct Dyn: 1-9, 2020 doi: 10.1080/07391102.2020.1763202 (Epub ahead of print).

141. Paintsil E and Cheng YC: Antiviral agents. Encyclopedia Microbiology: 176-225, 2019 doi: 10.1016/B978-0-12801238-3.02387-4.

142. Xing Y, Mo P, Xiao Y, Zhao O, Zhang Y and Wang F: Post-discharge surveillance and positive virus detection in two medical staff recovered from coronavirus disease 2019 (COVID-19), China, January to February 2020. Euro Surveill 25: 2000191, 2020.

This work is licensed under a Creative Commons Attribution-NonCommercial-NoDerivatives 4.0 International (CC BY-NC-ND 4.0) License. 